\title{
Alternate Protocol Identifier
}

National Cancer Institute

\section{Source}

National Cancer Institute. Alternate Protocol Identifier. NCI Thesaurus. Code C132344.

A unique code that identifies a specific protocol assigned by an affiliated governing body or other organization. 